\title{
International Comparative Assessment of Science and Mathematics Achievement in TIMSS
}

\author{
Yoon-Fah Lay ${ }^{1 *}$ \\ ${ }^{1}$ Faculty of Psychology and Education, Universiti Malaysia Sabah, Sabah, MALAYSIA
}

\begin{abstract}
INTRODUCTION
The International Association for the Evaluation of Educational Achievement (IEA) has pioneered international comparative assessments of educational achievement in the 1960s to gain a deeper understanding of the effects of policies and practices across countries' different systems of education. In particular, Trends in International Mathematics and Science Study (abbreviated as TIMSS) is directed by IEA's TIMSS \& PIRLS International Study Center at Boston College.

TIMSS has the goal of helping participating countries make informed decisions about how to improve teaching and learning in science and mathematics. TIMSS is a regular programme of student assessment at the fourth and eighth grade that has been conducted every four years since 1995. TIMSS provides participating countries with a wealth of information about trends in the science and mathematics knowledge and skills of their respective students. At the heart of TIMSS is a wide-ranging state-of-the-art assessment of how well students master the essential science and mathematics content, concepts, and procedures that countries expect them to learn as they progress through primary and lower secondary school.

This Special Issue provides a platform for researchers and practitioners in comparative assessment of science and mathematics achievement in TIMSS to present new research findings and insights for the betterment of science and mathematics education, nationally and internationally.
\end{abstract}

\section{ARTICLE SYNOPSIS}

For quick reference, a brief synopsis of each article is provided below:

\section{Effects of Early Numeracy Activities on Mathematics Achievement and Affect: Parental Value and Child Gender Conditions and Socioeconomic Status Mediation}

In this article, Chiu (2018) proposed models of (i) the multiple effects of early numeracy activities, conditioned by parental value, on mathematics achievement and affect (e.g., confidence and interest) and (ii) the multiple effects to be mediated by socioeconomic status and early numeracy activities conditioned by parental value and child gender. The proposed models were examined using Structural Equation Modeling (SEM) with data from Taiwanese parental reports and child grade- 4 tests and reports $(N=4,291 ; 49 \%$ girls) of TIMSS 2015. Three major results go beyond previous research findings and may provide recommendations for educational practices: (i) Early numeracy activities have effects on mathematics confidence and interest in addition to achievement, (ii) Socioeconomic status mediates the effects of early numeracy activities on achievement and confidence but not on interest. The mediating effect of socioeconomic status suggests that high-quality educational provision should be provided during early numeracy activities, (iii) Parents provide fewer numeracy activities for girls, which suggests that parents should provide more early numeracy activities to girls.

\section{Are Mathematics Curricula Harmonizing Globally Over Time? Evidence from TIMSS National Research Coordinator Data}

In this article, Johansson and Hansen (2019) examined whether national mathematics curricula in different educational systems harmonize over time given the impact of international large-scale assessments (ILSAs) on policy-making in different educational systems around the world. Data from the Trends in International Mathematics and Science Study (TIMSS) 2003, 2007, 2011, and 2015 were used to explore this issue. In addition to

(C) 2019 by the authors; licensee Modestum Ltd., UK. This article is an open access article distributed under the terms and conditions of the Creative Commons Attribution License (http://creativecommons.org/licenses/by/4.0/). \layyoonfah@yahoo.com.my (*Correspondence) 
background questionnaires given to students, teachers, and schools, a curriculum questionnaire was completed by each national research coordinator (NRC) in all participating countries in each TIMSS cycle. The analyses focused on the information about the extent to which the national mathematics curriculum covered certain topics in the subdomains of mathematics tested in TIMSS at Grade 8 level. Growth curve modeling and latent profile analyses were applied to uncover the development trend and countries' unobserved profiles in mathematics content domains of Number, Algebra, Geometry, and Data. Three clusters of countries were identified. Most countries belonged to the same profile in the later cycles of TIMSS. The study found indications of a general harmonization with respect to number of topics covered in countries' curricula over time, thus contributing to discussions of policy implications of a global curriculum.

\section{Non-Cognitive Factors Influencing Science Achievement in Malaysia and Japan: An Analysis of TIMSS 2015}

Japan's continual excellent achievement in TIMSS has led to many researches and discussions of the Japanese school system as a way of understanding the factors and system that underlie Japan's success in TIMSS. In this article, Mohtar, Halim, Samsudin, and Ismail (2019) examined the non-cognitive factors as plausible factors to students' TIMSS science achievement in Malaysia and Japan. The study adopted secondary data analysis in which the analysis was carried out on TIMSS 2015 data for respondents from Malaysia and Japan. This study proposed two models for each country which contained five constructs: four independent variables namely science teaching practices, victims of bullying, attitude towards science, school climate, and one dependent variable namely science achievement. Based on the structural model of multiple group comparison analysis, almost all non-cognitive factors in the model showed significant differences between the two countries except for the relationship between attitude towards science and science achievement in TIMSS.

\section{CONCLUSION}

It is hoped that the articles in this special issue will significantly contribute to international comparative assessment of science and mathematics education in TIMSS. It is also hoped that researchers and practitioners who are intrigued by comparative assessment of science and mathematics achievement in TIMSS will work together to resolve the lingering issues and address the emerging challenges of science and mathematics education at a global level. The ultimate goal of TIMSS is to provide participating countries with a wealth of information about trends in the science and mathematics knowledge and skills of their respective students and to help them make informed decisions about how to improve teaching and learning of science and mathematics in their respective countries.

\section{REFERENCES}

( ${ }^{*}$ These are articles published in this special issue.)

*Chiu, M.-S. (2018). Effects of early numeracy activities on mathematics achievement and affect: Parental value and child gender conditions and socioeconomic status mediation. Eurasia Journal of Mathematics, Science and Technology, 14(12), em1634. https:/ / doi.org/10.29333/ ejmste/97191

*Johansson, S., \& Hansen, K.Y. (2019). Are mathematics curricula harmonizing globally over time? Evidence from TIMSS national research coordinator data. Eurasia Journal of Mathematics, Science and Technology, 15(2), em1656. https://doi.org/10.29333/ejmste/99516

*Mohtar, L.E., Halim, L., Samsudin, M.A., Ismail, M.E. (2019). Non-cognitive factors influencing science achievement in Malaysia and Japan: An analysis of TIMSS 2015. Eurasia Journal of Mathematics, Science and Technology, 15(4), em1697. https:/ / doi.org/10.29333/ ejmste/103567

\section{http://www.ejmste.com}

